\title{
Investigating the Critical Issues for Enhancing Sustainability in Higher Education Institutes in Thailand
}

\author{
Allan Sriratana Tabucanon ${ }^{1}$, Alisa Sahavacharin ${ }^{2}$, San Rathviboon ${ }^{3}$, Husna Lhaetee ${ }^{1}$, Dhitiya Pakdeesom ${ }^{1}$, Wenchao \\ $\mathrm{Xue}^{4}$, Kitikorn Charmondusit ${ }^{1 *}$ \\ ${ }^{1}$ Faculty of Environment and Resource Studies, Mahidol University, Nakhon Pathom 73170, Thailand \\ ${ }^{2}$ Faculty of Architecture and Planning, Thammasat University, Prathumthani 12121, Thailand \\ ${ }^{3}$ Information Technology Department, Chulabhorn Royal Academy, Bangkok 10210, Thailand \\ ${ }^{4}$ Department of Energy, Environment and Climate Change, School of Environment, Resources and Development, Asian \\ Institute of Technology, Pathum Thani 12120, Thailand
}

Corresponding Author Email: kitikorn.cha@mahidol.ac.th

https://doi.org/10.18280/ijsdp.160311

Received: 26 March 2021

Accepted: 4 June 2021

\section{Keywords:}

Higher Education Institute, sustainability,

UI GreenMetric, Prioritized sustainability

dimensions and issues

\begin{abstract}
Higher Education Institutions (HEIs), by and large, have increasingly committed to integrate sustainable development (SD) into their policies, practices, and programs. Recently, there have been several sustainability assessment tools specifically developed for HEIs. Many HEIs, especially small-to-middle sized HEIs in Thailand, are planning to enhance SD but are reluctant due to resource requirements. This study was conducted to investigate important sustainability implementation issues, including the effect of HEI sizes and UI GreenMetric participation. A weighting approach on sustainability dimensions and issues was utilized, and HEI's sustainability reports and official websites were reviewed to evaluate their sustainability performance of large-, middle-, and small-sized HEIs as well as UI GreenMetric participants and non-participants in Thailand. The findings reveal that the issues of the sustainabilityintegrated vision and strategy, safety and well-being, waste, and the SD-enhancing educational system were fundamentally critical for HEI sustainability. Moreover, most of the large-sized HEIs in Thailand that participated in UI GreenMetric were evaluated to have higher sustainability performance than others, apparently in administration, environment, and education/research dimensions. This study supports the necessity for a sustainability assessment tool for HEIs.
\end{abstract}

\section{INTRODUCTION}

Sustainable development is defined as "development that meets the needs of the present without compromising the ability of future generations to meet their own needs" [1]. In the implementation of Agenda 2030 and the Sustainable Development Goals (SDGs), SDG 4 (Quality Education) is considered an enabler for other goals; hence, transformation of Higher Education Institutions (HEIs) to function and practice sustainability, i.e., balancing mutual benefits among economic, social, and environment dimensions, is imperative. HEIs have played important roles in promoting sustainable development through creating awareness, generating and disseminating knowledge, and developing skills of people, especially students, aiming for contribution to sustainability [2-4] through their "lead by example" approach [5]. Therefore, HEIs have committed to implement projects and initiatives to incorporate the concept of sustainable development into their systems [6-8].

As sustainability monitoring and evaluation guidelines are useful for HEIs to publicly disseminate their sustainability efforts, a variety of HEI sustainability assessment tools have been developed and are being widely used (e.g., American College \& University Presidents' Climate Commitment [9]; Global Reporting Initiative [10]; Association for the
Advancement of Sustainability in Higher Education [11]; Universitas Indonesia [12]; Times Higher Education [13]). Berzosa et al. [14] addressed the necessity for sustainability tools for promoting integration of sustainability into strategies and activities in HEIs, which utilize numerous indicators that HEIs are required to submit. For example, Sustainability Tracking Assessment and Rating System (STARS), Time Higher Education Impact University (THE), and UI GreenMetric University Rankings (UI GreenMetric) have 68, 75, and 69 sustainability-related indicators or issues, respectively. This may create difficulties for new HEI participants in using those tools, especially for small-tomiddle-sized HEIs with limited resources for data collection and implementation. The sustainability report of Global Reporting Initiatives (GRI) is widely considered to be an appropriate tool [15-18], due to its accommodation of comprehensive issues with flexibility for reporters enabling selected issues that are significant and relevant to the organization. However, GRI is not specifically designed for HEIs, which lack education and research programs [19]. Hence, recommended sets of prioritized indicators or issues would facilitate and encourage implementation for those new HEIs that are inexperienced in sustainability promotion.

Another important factor that is hypothesized to influence sustainability achievement is size. Larger firms have attracted 
more attention from media and stakeholders due to their legitimacy and their reputation [20, 21]. Bansal [22] indicated a positive relationship between size and corporate sustainable development. However, Gallo and Christensen [23] argued that there was no significant finding on size and the propensity of a firm's sustainability reporting. The effects of size as well as HEI participation in utilizing sustainability tools on its sustainability performance, especially in a developing country, have not been found. In addition, according to our pre-survey, such research questions were usually inquired by the executive of HEIs in Thailand.

In Thailand, there are a total of 138 HEIs. UI GreenMetric and THE are the only tools that have been widely adopted; 37 HEIs and 19 HEIs participated, respectively, in 2019. Considering the size of the submitting HEIs by UI GreenMetric, 56.8\% was large-sized HEIs, and the remaining $43.2 \%$ included small-to-medium-sized HEIs and private HEIs. In the case of THE, these numbers were $79.0 \%$ and $21 \%$, respectively.

As mentioned earlier, the objectives of this study were to investigate which sustainability dimensions and issues should be primarily considered to be implemented at the initial stage for new HEIs that are inexperienced in sustainability assessment in the context of Thai HEIs. Twenty-one experts were provided a questionnaire to score all dimensions and issues that can lead to prioritized sets of sustainability issues. Furthermore, the effect of institute size and UI GreenMetric participation on sustainability performance, based on the questionnaire results, was further evaluated through reviewing policies, strategies, and sustainability-related activities which are published online by the selected HEIs.

\section{LITERATURE REVIEWS}

\subsection{Sustainability dimensions and issues}

Recent studies addressed further expansion of dimensions to be integrated for HEI cases. Alghamdi et al. [24] reviewed 12 sustainability assessment tools. The identified common issues include management, academia, environment, engagement, and innovation. At the same time, Gómez et al. [25] concluded 4 dimensions, namely, operations, education and research, public engagement, and administration, that were fundamental for the sustainability of HEIs. Additionally, a number of sustainability-related dimensions and issues differ across sustainability assessment tools. For example, Global Reporting Initiative [10], Advancement of Sustainability in Higher Education [11], Universitas Indonesia [12], and Times Higher Education [13], respectively, contain 4 dimensions (institutional characteristics, economics, environment, and society) with 117 issues, 6 dimensions, (institutional characteristics, academics, engagement, operations and planning, administration, and innovation and leadership) with 69 issues, 6 dimensions (waste, water, transportation, energy and climate change, education, and setting and infrastructure) with 39 issues, and 17 dimensions in accordance with the sustainability goals of the United Nations with 65 issues.

\subsection{Prioritization of sustainability dimensions and issues}

In accordance with Lozano [18], sustainability reporting, which is voluntary for HEIs, has two objectives. The first one is assessment of the current state process toward reaching sustainable development, and the second is to serve as an instrument for communication with stakeholders. HEIs need to report their sustainable development situation through an annual report or sustainability report, which can be used for monitoring, analyzing, and controlling the performance of sustainable development practices of the institutions [26].

Fonseca [27] reviewed Global Reporting Initiative's sustainability report of 25 of Canada's largest universities and addressed the limitation of the scopes, emphasizing on ecoefficiency towards green buildings and procurement (71\% selected by the universities) and environmental performance (53\%). As for curriculum, teaching, research, economic performance, human right issues, and society issues, these were still very limited. This corresponds to Filho [28], who explained that a green university is considered a first step towards a sustainable university.

Gómezgutiérrez and Sepúlveda [19] reviewed a sustainability report under the guideline of Global Reporting Initiatives from 26 Colombian HEIs. The results indicated 23 most reported issues, which were found with a frequency higher than $50 \%$ overall in 26 HEIs. Specifically, the issues, with the selection above $80 \%$, include direct economic value generated and distributed (EC1), direct energy consumption by primary energy source (EN3), and total workforce by employment type, employment contract, region, and gender (LA1).

In the case of South East Asian countries, including Thailand, this type of analysis is still not implemented, although the information is necessary for HEIs to choose what should be done as the first step towards a sustainable university. Apart from HEIs, other countries or sectors have their own priority issues. For example, Whitehead [29] identified the highest priority of sustainability indicators for the New Zealand wine industry by using materiality analysis. The finding addressed a common bias in agricultural sustainability assessment towards environmental issues, followed by social issues. Economic and governance issues were, therefore, not found to be high priorities.

\subsection{Effect of sustainability tool participation on sustainability implementation in HEIs}

Filho et al. [30] showed that Green Offices and similar governance structures in HEIs may assist efforts within HEIs to work in the field of sustainable development. However, there are constraints arising from political belief, financial limitations and lack of materials, and limitations of expertise, which is a complex endeavor that faces many challenges.

Atici et al. [31] investigated the relationship between "being green" and academic performance in reference, respectively, to UI GreenMetric and academic rankings, including Academic Ranking of World Ranking, QS World University Ranking, Time Higher Education World University Rankings, and National Taiwan University Ranking. The conclusion reveals a positive relationship between UI GreenMetric Rankings and the competitiveness advantage for the world university rankings.

\section{MATERIALS AND METHOD}

\subsection{Development of sustainability dimensions and issues}

According to our extensive literature reviews, there are 
currently 26 sustainability assessment tools, as listed in Caeiro et al. [32], of which 7 tools were selected based on the following criteria and analyzed. Four criteria were applied for selection, namely, that the tools are widely recognized from research articles, availability of an official website, extensive adoption from HEIs, and accessibility to a comprehensive guideline. These are to ensure that the selected tools are widely accepted for the assessment due to its theoretical reliability and practicality. All indicators were re-grouped into relevant issues under 5 dimensions, including economic, social, environment, administration, and education/research.

\subsection{Weighted scoring of sustainability dimensions and issues}

The developed dimensions and issues, as described in Section 3.1, were scored by 21 experts comprising executive representatives of Thai HEIs, whose main responsibility is promoting their campus sustainability through the developed questionnaire. The total score of 100 was requested to be distributed across dimensions and issues. Such prioritization was performed to highlight dimensions and issues that are important to enhance the sustainability of HEIs in the context of Thailand. The questionnaire in this study was approved by the Institutional Review Board (IRB). ANOVA followed by post-hoc Tukey Honestly Significant Difference (HSD) was then applied to assess the significant differences of means among dimensions and issues.

\subsection{Categorization of HEIs and data collection}

According to the Office of the Higher Education Commission of Thailand, 138 HEIs have been established. HEIs are categorized into 2 types, governmental HEI and private HEI. The former institutions are further categorized with respect to size. Large HEIs have an annual financial support from the government of Thailand of more than 1 billion Baht (32 million USD as of 7 September 2020), while middle size HEIs receive between 500 million Baht and 1 billion Baht (between 16 million USD and 32 million USD as of 7 September 2020). Small size institutions have an annual income lower than 500 million Baht (16 million USD as of 7 September 2020). Private HEIs do not receive financial support from the government. In this study, only governmental HEIs were considered due to the accessibility of their online information.

HEIs in Thailand were randomly selected totaling 12 largesized HEIs, 14 middle-sized HEIs, and 10 small-sized HEIs. Those HEIs were also classified into two groups, which were 17 UI GreenMetric participants and 19 non-participants. UI GreenMetric ranking has been regarded as the most recognized sustainability assessment tool that Thai HEIs have been involved in, and there were 37 HEIs who participated in 2019.

The national HEIs need to publish their annual report. Recently, websites have become an effective form of communication with the public. Therefore, published reports, including the annual report and sustainability report, and the official websites of the selected HEIs were reviewed on HEI implementation of sustainability activities concerning the developed issues. The time frame of the implementation for the review was between October 2018 and September 2019, as it was the 2019 fiscal year of the Thai government. The detected activities (yes or no) were then matched with the issues. Furthermore, the information was compared in the percentage between UI GreenMetric participants and nonparticipants to describe the different implementation based on sustainability issues and to observe the considered activities revealed in the reports.

\subsection{Comparison of sustainability-related activities across HEIs}

The weighting score was applied to each issue in order to calculate performance scores across issues and key elements, as shown in Eqns. (1) and (2):

$$
\begin{gathered}
P I_{i j k}=\alpha_{i} \times D A_{i j} \\
P D_{j k}=\sum_{i=1}^{n} \sum_{j=1}^{n} \sum_{k=1}^{n} P I_{i j k}
\end{gathered}
$$

where:

$P I_{i j}$ represents the performance score of issue $i$ in HEI $j$, $\alpha_{i}$ is the weighted score of issue $i$,

DAij is the detected activities of issue $i$ in $\operatorname{HEI} j$ (Yes $=1$, No $=$ $0)$,

$P D_{j k}$ represents the overall performance score of HEI $j$ on dimension $k$,

$P I_{i j k}$ is the performance score of issue $i$ in $\mathrm{HEI} j$ on dimension $k$.

Pearson correlation ( $r$ ) was applied to investigate correlation coefficients between Administration (AD) issues and other issues (economic, environment, social, and education/research related issues). It is hypothesized that the $\mathrm{AD}$ dimension contains principal issues to promote sustainability actions in other issues. Moreover, principal component analysis (PCA), a multivariate statistical technique, was used to investigate the propensity of dimension sustainability implementation in relation to the overall sustainability performance scores across the HEI categories.

\section{RESULTS AND DISCUSSION}

\subsection{Sustainability issues}

The analysis of 7 sustainability assessment tools is summarized in Table 1. 25 sustainability issues were developed in which 3 issues belong to Administration, 5 issues for Social, 4 issues for Economic, 10 issues for Environment, and 3 issues for Education/research. Economic, Social, and Environment are regarded as dimensions of sustainability [33]. Administration is essential for the development of sustainability initiatives, especially for sustainability-related organization, policy, strategy, integrity, and ethics. Therefore, it was separated into one of the developed dimensions. Meanwhile, Education/Research is the main academic duty of HEIs, which should be separated into another dimension [25]. Our dimension categorization is different from others that have been mentioned in literature review Section 2.1 in that we highlight the importance of Administration and Education/research in the context of HEIs. Hence, the relating issues could be clearly re-grouped into those dimensions, increasing their appearance and, consequently, receiving more attention from the questionnaire respondents. The detailed description of each dimension is provided below. 
Table 1. Sustainability assessment tools considered in this study

\begin{tabular}{|c|c|c|c|c|c|}
\hline No. & Tools & Developed by & Descriptive & $\begin{array}{c}\text { Number of Dimensions / } \\
\text { criteria / indicators }\end{array}$ & Reference \\
\hline 1 & $\begin{array}{l}\text { Alternative } \\
\text { University } \\
\text { Appraisal }\end{array}$ & $\begin{array}{l}\text { ProSPER.Net Joint Project } \\
\text { on "Alternative University } \\
\text { Appraisal" led by Hokkaido } \\
\text { University, with funds } \\
\text { through the United Nations } \\
\text { University Institute for the } \\
\text { Advanced Study of } \\
\text { Sustainability (UNU-IAS) }\end{array}$ & $\begin{array}{l}\text { AUA focused on Education for Sustainable } \\
\text { Development (ESD), which propose to } \\
\text { increase the awareness and education related } \\
\text { sustainability. The institutions can } \\
\text { demonstrate the best implementation to the } \\
\text { others for exchanges. The major goal of } \\
\text { AUA is external engagement, which HEIs } \\
\text { can share the initiatives and implementation } \\
\text { with each other more than the ranking } \\
\text { competition. }\end{array}$ & $\begin{array}{l}3 \text { parts, } 4 \text { dimensions } \\
\text { (Governance, Education, } \\
\text { Research, and Outreach) } \\
18 \text { criteria } \\
36 \text { indicators }\end{array}$ & [34] \\
\hline 2 & $\begin{array}{c}\text { Auditing } \\
\text { Instrument for } \\
\text { Sustainability in } \\
\text { Higher Education } \\
\text { (AISHE) }\end{array}$ & $\begin{array}{l}\text { Dutch Foundation for } \\
\text { Sustainable Higher } \\
\text { Education }\end{array}$ & $\begin{array}{c}\text { AISHE is the assessment tool for } \\
\text { developing the sustainable policies in HEIs, } \\
\text { which is adapted from the European } \\
\text { Foundation for Quality Management } \\
\text { Excellence Model. The steps of evaluation } \\
\text { follow the PDCA cycle (Plan, Do, Check, } \\
\text { and Act). }\end{array}$ & $\begin{array}{c}5 \text { dimensions } \\
\text { (Mission, Operations, } \\
\text { Education, Research, } \\
\text { Society) } \\
30 \text { indicators }\end{array}$ & [35] \\
\hline 3 & $\begin{array}{c}\text { College } \\
\text { Sustainability } \\
\text { Report Card }\end{array}$ & $\begin{array}{l}\text { Sustainable Endowments } \\
\text { Institute }\end{array}$ & $\begin{array}{l}\text { College Sustainability Report Card, or } \\
\text { Green Report Card, was established to } \\
\text { evaluate the sustainability for Canadian and } \\
\text { American HEIs, which need to be calculated } \\
\text { in the same way of GPA and converted to A } \\
\text { (4 scores), B ( } 3 \text { scores), C ( } 2 \text { scores), D (1 } \\
\text { scores), or F (0 scores) }\end{array}$ & $\begin{array}{c}9 \text { dimensions } \\
\text { (Administration, Climate } \\
\text { Change \& Energy, Food \& } \\
\text { Recycling, Green Building, } \\
\text { Student Involvement, } \\
\text { Transportation, Endowment } \\
\text { Transparency, Investment } \\
\text { Priorities, Shareholder } \\
\text { Engagement) } \\
\text { 52 indicators }\end{array}$ & [36] \\
\hline 4 & \begin{tabular}{|c|} 
Global Reporting \\
Initiative's \\
Sustainability \\
Report
\end{tabular} & $\begin{array}{c}\text { Global Reporting Initiative } \\
\text { (GRI) }\end{array}$ & $\begin{array}{l}\text { GRI can be applied to assess the } \\
\text { sustainability in the organizations, which } \\
\text { can make them understand their situations, } \\
\text { processes, and impacts on sustainability } \\
\text { development. It has been accepted in } \\
\text { international levels for sustainable } \\
\text { assessment and propagandize for external } \\
\text { society. }\end{array}$ & $\begin{array}{c}3 \text { dimensions } \\
\text { (Economic, Environment, } \\
\text { Social) } \\
43 \text { criteria } \\
136 \text { indicators }\end{array}$ & [10] \\
\hline 5 & \begin{tabular}{|c|} 
Sustainability \\
Assessment of \\
Food and \\
Agriculture \\
Systems (SAFA)
\end{tabular} & $\begin{array}{c}\text { Food and Agriculture } \\
\text { Organization (FAO) }\end{array}$ & $\begin{array}{l}\text { SAFA is the assessment tool for } \\
\text { sustainability of food and agriculture } \\
\text { systems evaluation. This tool was developed } \\
\text { for driving food production and agriculture } \\
\text { to reach the sustainability (sustainability } \\
\text { supply chain), which covered food and } \\
\text { agricultural supply chain from raw } \\
\text { materials, production systems, and } \\
\text { distribution to the customers. }\end{array}$ & $\begin{array}{c}4 \text { dimensions } \\
\text { (Environmental Integrity, } \\
\text { Economic Resilience, Social } \\
\text { Well-being, Good } \\
\text { Governance) } \\
21 \text { indicators }\end{array}$ & [37] \\
\hline 6 & $\begin{array}{l}\text { Sustainability } \\
\text { Tracking } \\
\text { Assessment and } \\
\text { Rating System } \\
\text { (STARS) }\end{array}$ & $\begin{array}{l}\text { Association of the } \\
\text { Advancement of } \\
\text { Sustainability in Higher } \\
\text { Education (AASHE) }\end{array}$ & $\begin{array}{l}\text { STARS is the assessment tools for HEIs in } \\
\text { Canadian and American institutions. These } \\
\text { tools are utilized for assessment of campus } \\
\text { efforts to achieve sustainable institutions } \\
\text { through initiatives or implementation. The } \\
\text { results are divided into } 4 \text { levels, including } \\
\text { Bronze, Silver, Gold, and Platinum, in } \\
\text { which the scores depend on the percentage } \\
\text { of sustainable implementations. }\end{array}$ & $\begin{array}{c}5 \text { dimensions } \\
\text { (Academics, Engagement, } \\
\text { Operations, Planning \& } \\
\text { Administration, Innovation \& } \\
\text { Leadership) } \\
68 \text { indicators }\end{array}$ & [11] \\
\hline 7 & \begin{tabular}{|c|} 
Time Higher \\
Education Impact \\
University \\
Rankings
\end{tabular} & $\begin{array}{l}\text { Time Higher Education } \\
\text { (THE) }\end{array}$ & $\begin{array}{l}\text { THE tools evaluate against the United } \\
\text { Nation's Sustainability Development Goals } \\
\text { (SDGs). The major criteria of evaluation } \\
\text { covered } 17 \text { goals of SDGs. }\end{array}$ & $\begin{array}{l}17 \text { dimensions } \\
\text { (17 SDG goals) } \\
75 \text { indicators }\end{array}$ & [13] \\
\hline 8 & $\begin{array}{l}\text { UI GreenMetric } \\
\text { University } \\
\text { Rankings }\end{array}$ & Universitas Indonesia & $\begin{array}{l}\text { UI Greenmentric was used to assess the } \\
\text { efforts of developed green university } \\
\text { activities in HEIs. Furthermore, HEIs can } \\
\text { share the best practices to the others } \\
\text { institutions. }\end{array}$ & $\begin{array}{c}6 \text { dimensions } \\
\text { (Setting and Infrastructure, } \\
\text { Energy and Climate Change, } \\
\text { Waste, Water, } \\
\text { Transportation, Education) } \\
69 \text { indicators }\end{array}$ & [12] \\
\hline
\end{tabular}

4.1.1 Administration (AD)

Organizational management (AD1) assesses the enhancing sustainability implementation by the institute systems in the campus. This issue addresses the necessity for an officially 
appointed committee or officer with a particular responsibility for developing sustainability policies and strategies as well as overseeing implementation and assessment concerning sustainability actions in the institute.

Vision and strategy (AD2) emphasize the institute's current policy and strategy and whether they are related to sustainability, which are essential initiatives of governance. The practical evaluation was based on keyword "sustainability" or "sustainable development" indicated in either policy or strategic planning.

Integrity and ethic (AD3) necessitate the awareness of the staff on integrity and ethics for performing any task. The institute provided clear regulation or code of practices or courses specifically designed for executives, academic staff, supporting staff, and students.

\subsubsection{Social (SC)}

Safety and well-being (SC1) investigate safety management and operation and the health promotion of stakeholders. The institute sets a zero-accident target and discloses accidental records to the public. It is noteworthy that safety is a fundamental requirement for institute well-being; therefore, safety and well-being were combined. Regarding well-being, it was demonstrated through the institute's effort and plans for the adequate provision of facilities required for good living.

Social, equity, rights, fairness, and freedom (SC2) assess the wages of staff, which should be fair regardless of gender, as well as educational accessibility for students, including opportunities for poor and disabled students. Furthermore, the institute created an environment of freedom for research conduct and opened a platform for any activities that were not unlawful.

Public engagement (SC3) encourages the institute's activities to be mutually cooperated with communities or other sectors to enhance the communities' sustainability. Such activities should be able to demonstrate social impact, such as increased income, new opportunities for jobs, better environmental quality, or improved well-being in the communities.

Social transparency (SC4) discloses administrative activities in the institute to the public and external stakeholders (community, government sectors, or private sectors). All stakeholders participate in voting related to an institute's executive decision or could be able to request a result of voting for investigation.

Socioeconomic consideration for supplier (SC5) selects a supplier's products or services that integrated sustainability into their policy, strategy, and implementation as well as strictly complied with the national regulations. In addition, the supplier with international certification was particularly considered.

\subsubsection{Economic (EC)}

Economic transparency (EC1) discloses monetary income and expenditures that should be presented in public to demonstrate the financial performance of the institute. In Thailand, this information was generally disclosed to public via an annual report.

Economic performance and distribution (EC2) examine the proportion of income and expenditures, and extensiveness of monetary distribution to the institution's staff and communities. In particular, the outcome of the distribution should be able to demonstrate its consequence for economic growth in the communities.
Financial mechanism promoting sustainable development investment (EC3) investigates a developed protocol to stimulate investment for promoting sustainable development, including equipment, infrastructure, program, and research. The institution may establish a sustainability fund specifically supporting those activities or projects that were successfully demonstrated to contribute to the sustainability of the institute.

Indirect economic impacts (EC4) are concerned about the investment for public infrastructure, enhancing safety, wellness, or economic growth of the community. The definition of indirect impacts is that the contribution is not in monetary form but rather in infrastructure, such as a bridge, a research center, computers enabling educational accessibility, or a museum located in the community.

\subsubsection{Environment (EN)}

Building and construction (EN1) address the use of environmentally-friendly materials in a building as well as the building design for the purpose of low energy consumption. This can be demonstrated by an international or national certification.

Climate change (EN2) relates to an estimation of the greenhouse gas emission from activities implemented by the institute. Furthermore, the institution should address a reduction target in correspondence with national needs.

Transportation (EN3) includes alternative transportation for staff, students, and visitors, such as buses, trams, bicycles, or walking to reduce the use of private vehicles on campus. Furthermore, the adoption of clean energy for public transport, which can lead to improved air quality, was also optional.

Waste (EN4) investigates the institution's solid waste management with the concept of $3 \mathrm{R}$, consisting of reduce, reuse, and recycle principles.

Food and dining (EN5) focus on food waste management, food security, use of environmentally-friendly food, and drinking water containers.

Energy conservation and efficiency (EN6) are concerned about measures for effective consumption of energy in the institute's building by reducing energy usage, using a clean technology to utilize renewable energy sources, and applying eco-efficiency concepts.

Environmental regulation compliance (EN7) discloses all information regarding pollution emission from the institution's operational activities to the environment and whether it strictly complied with the national standards. The institution should ensure that their operation minimized all possible environmental impacts. In addition, the institution should have an environmental emergency response.

Green purchasing (EN8) focuses on the preference for selecting environmentally-friendly office products that were certified by national or international standards.

Ecosystem (EN9) encourages an increase in green areas where a local plant and animal conservational promotion was prioritized.

Water (EN10) investigates water consumption and management in the campus with the aim of minimizing water usage as well as enhancing water recycling. In addition, accessibility to drinking water that is free of charge was also covered in this topic.

\subsubsection{Education and research (ER)}

SD-enhancing educational system (ER1) contributes to student's sustainability knowledge and encourages participation in activities related to sustainability. The 
implementation includes pre- and post-evaluation tests on sustainability knowledge, an innovation contest for a sustainable campus, and an academic conference as a platform for students to share any projects contributing to sustainability.

SD-integrated curriculum (ER2) evaluates the institute's curriculum by mapping with SDGs to investigate any gap that a new course or a program should be developed in order to be fulfilled.

SD-related research (ER3) evaluates research contributing to sustainability via academic journal publications. It also includes a supporting fund for researchers and staff to develop an academic profession in a sustainability field. Corresponding to SD-integrated curriculum, research outputs were mapped in accordance with SDGs to investigate any gaps and needs.

Overall, the number of environmental issues is the largest. This supports the conclusion reached by Alghamdi et al. [24] that the number of environmental issues is the highest number of issues in the reviewed tools. Then, this is followed by social and economic issues, while administration is equal to education/research. This is due to a large diversity of environmental concerns involving physical elements, such as quality of air and water through environmentally-friendly transportation, energy savings and efficiency, greenhouse gas emission reduction, management of waste in both solid and liquid forms, and biological elements, which are environmental conservation and biodiversity promotion issues.

\subsection{Weighted sustainability dimensions and issues}

Based on the expert weighting on dimensions and issues illustrated in Figure 1, ANOVA test with post-hoc Tukey HSD indicated $\mathrm{AD}$ was the most critical dimension for implementing sustainability activities in HEIs (27.84 points, \pm $10.85 \mathrm{SD})(\mathrm{P}<0.05)$. This is due to its enhancement of resource management to sustainability implementation, improved plans to move towards sustainability, and engagement of students, staff, and stakeholders in governance as well as providing clear direction for budgeting [11]. The following is ER (21.86 points, $\pm 8.05 \mathrm{SD})$. HEIs have responsibilities for enhancing knowledge, awareness, technology, and facilities to make future environmental sustainability. HEIs provide profession and knowledge in all dimensions to improve an intelligent conceptual framework for achieving sustainable development. Therefore, education and research play a crucial role in creating a sustainable future $[2,38]$. In the case of EC, SC, and EN, they were statistically equal in importance $(\mathrm{P}<0.05)$. This result contradicts with results reported by Velazquez et al. [39] and Sepasi et al. [40], who concluded that environmental indicators were often a major measurement rather than social or economic variables.

Within the $\mathrm{AD}$ dimension, Vision and strategy (AD2) (41.91 points, \pm 15.69 SD) was regarded as the most important issue $(\mathrm{P}<0.05)$. Vision of the institute's executives is necessarily required as a first procedure that leads to sustainability-related missions, goals, policies, and strategic planning with clear, consistent directions [39, 41]. Furthermore, sustainability-integrated vision facilitates establishment of a sustainability office or committees who are responsible for the development of the sustainabilitypromoting policies and strategies, as well as overseeing and monitoring their relevant activities. Such an establishment consequently contributes to good Organizational Management (AD1) and strict consideration of Integrity and ethics (AD3) involved in the institute's activities. However, AD1 and AD3 were not statistical different $(\mathrm{P}=0.937)$. It is noteworthy that this result may be influenced by the questionnaire respondents who were mostly executives with a duty to promote campus sustainability. Hence, AD2 is the top priority in order to obtain financial support for the promotion [29]. For future studies, it is recommended to have more diverse respondents that represent a broader range of stakeholders, including nonexecutives, such as academic staff, supporting staff, and surrounding communities that provide a wider view of the issues. However, the respondents should have adequate knowledge in sustainability prior to scoring.

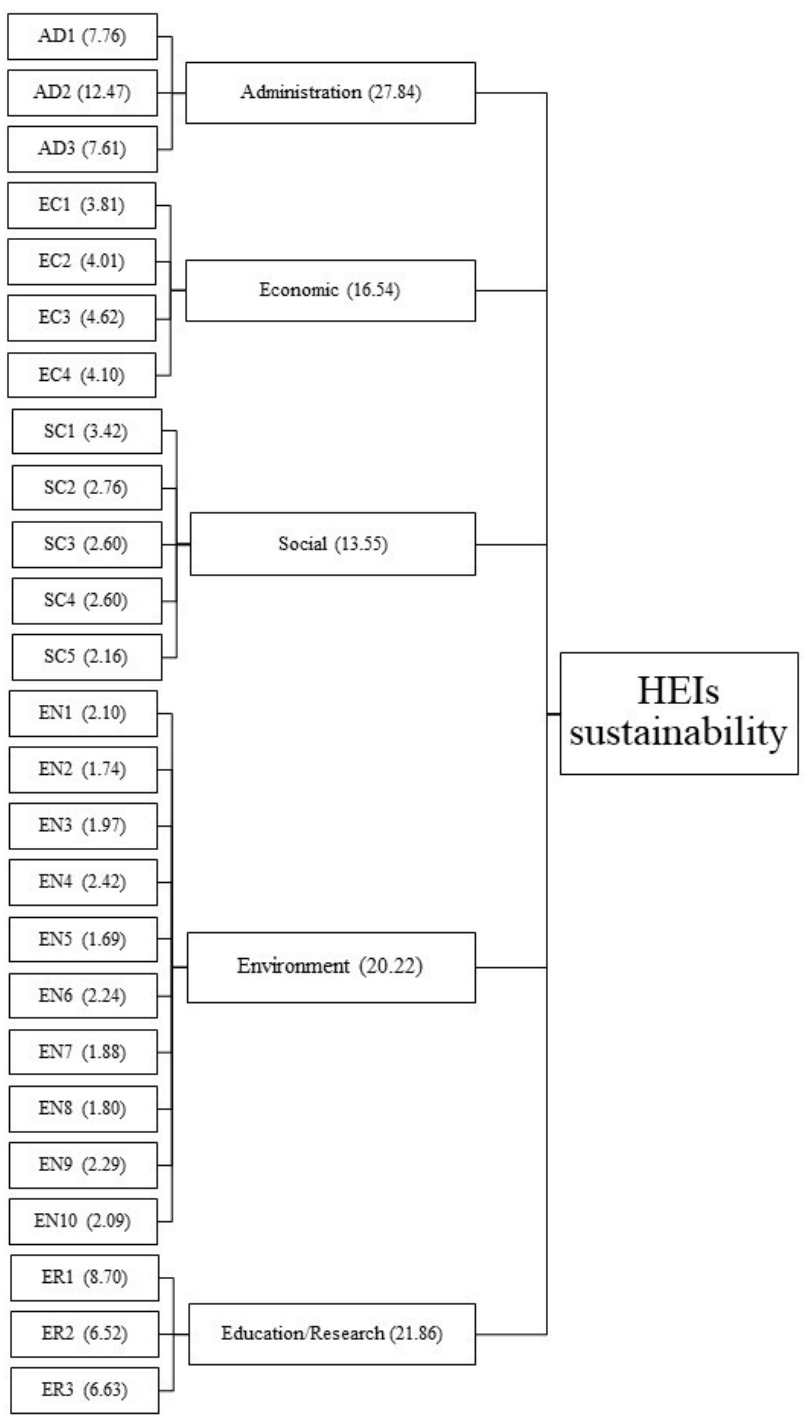

Figure 1. Weighting result on developed sustainability dimensions and issues by experts

Regarding the SC dimension, only the score of Safety and well-being (SC1) (25.95 points, $\pm 11.47 \mathrm{SD}$ ) was statistically the highest $(\mathrm{P}<0.05)$, while other issues were identical $(\mathrm{P}>$ $0.05)$. SC1 was a complex inter-linked issue involving other social and environmental issues $[18,42]$. As shown in Table 2, there were 12 HEIs that did not address SC1 in the report. It is apparent that the HEIs without SC1 mostly lack implementation related to Social transparency (SC4), Socioeconomic consideration for supplier (SC5), Food and dining (EN5), Environmental regulation compliance (EN7), Green purchasing (EN8), Ecosystem (EN9), and SDenhancing educational system (ER1), evidencing the lack of 
interlinking between SC1 and others $[42,43]$.

Considering the EC dimension, there was no statistical difference among the related issues $(\mathrm{P}>0.05)$. It should be noted that the entire group of experts who were involved in the weighting procedure was dispatched from public HEIs, which are not-for-profit. This might result in an equal weighting distribution across economic-related issues.

In EN issues, Waste (EN4) was evaluated to be important, as it was higher over 4 issues $(\mathrm{P}<0.10)$, respectively. Tangwanichagapong et al. [7] demonstrated that many HEIs in Thailand have committed to create green campuses with the concept of 3Rs (reduction, reuse, and recycling) of waste. As for other EN-related issues, their comparison was inconclusive. The result is consistent with Freidenfelds et al. [44], who highlighted energy, water, transport, waste, behavior, and management to be significant indicators towards a green university. It is also true in our study that there was no significant difference in the weighting results among
Transport (EN3), Energy conservation and efficiency (EN6), and Water (EN10), indicating their equal importance. It is widely recognized that Climate Change (EN2) has received attention globally due to the increased concern on climate change mitigation and adaptation. Thailand has committed the country's mitigation efforts through submission of Nationally Determined Contribution (NDC) to the United Nations Framework Convention on Climate Change (UNFCCC) in 2015. In fact, HEIs can produce a significant amount of greenhouse gas through a variety of activities [45]. HEIs, as a role model for students through leading by example, should also prioritize climate change issues in support of reducing greenhouse gas emissions. Nevertheless, the Climate Change (EN2) weight was relatively low. This may be due to overlapping measures with Building and construction (EN1), Transport (EN3), Waste (EN4), Energy conservation and efficiency (EN6), Ecosystem (EN9), and Water (EN10), which would result in underscoring of the climate change issue.

Table 2. Checklist of sustainability issues implemented by the reviewed HEIs

\begin{tabular}{|c|c|c|c|c|c|c|c|c|c|c|c|c|c|c|c|c|c|c|c|c|c|c|c|c|c|}
\hline HEI* & $\mathrm{AD}$ & $\mathrm{AD}$ & $\mathrm{AD}$ & $\mathrm{SC}$ & $\mathrm{SC}$ & $\mathrm{SC}$ & $\mathrm{SC}$ & $\mathrm{SC}$ & $\mathrm{EC}$ & $\mathrm{EC}$ & $\mathrm{EC}$ & $\mathrm{EC}$ & $\mathrm{EN}$ & $\mathrm{EN}$ & $\mathrm{EN}$ & $\mathrm{EN}$ & $\mathrm{EN}$ & $\mathrm{EN}$ & $\mathrm{EN}$ & $\mathrm{EN}$ & $\mathrm{EN}$ & EN1 & ER & ER & ER \\
\hline HEI* & 1 & 2 & 3 & 1 & 2 & 3 & 4 & 5 & 1 & 2 & 3 & 4 & 1 & 2 & 3 & 4 & 5 & 6 & 7 & 8 & 9 & 0 & 1 & 2 & 3 \\
\hline L1 & $\checkmark$ & $\checkmark$ & $\checkmark$ & $\checkmark$ & $\checkmark$ & $\checkmark$ & & $\checkmark$ & $\checkmark$ & $\checkmark$ & $\checkmark$ & & $\checkmark$ & $\checkmark$ & $\checkmark$ & $\checkmark$ & & $\checkmark$ & & & $\checkmark$ & $\checkmark$ & & $\checkmark$ & $\checkmark$ \\
\hline L2 & $\checkmark$ & $\checkmark$ & & $\checkmark$ & $\checkmark$ & $\checkmark$ & & & $\checkmark$ & $\checkmark$ & $\checkmark$ & $\checkmark$ & $\checkmark$ & $\checkmark$ & $\checkmark$ & $\checkmark$ & $\checkmark$ & $\checkmark$ & & & $\checkmark$ & $\checkmark$ & & $\checkmark$ & \\
\hline L3 & $\checkmark$ & $\checkmark$ & $\checkmark$ & $\checkmark$ & $\checkmark$ & $\checkmark$ & $\checkmark$ & & $\checkmark$ & $\checkmark$ & $\checkmark$ & & $\checkmark$ & $\checkmark$ & $\checkmark$ & $\checkmark$ & & $\checkmark$ & & & $\checkmark$ & $\checkmark$ & $\checkmark$ & $\checkmark$ & $\checkmark$ \\
\hline L4 & $\checkmark$ & $\checkmark$ & $\checkmark$ & $\checkmark$ & $\checkmark$ & $\checkmark$ & & & $\checkmark$ & $\checkmark$ & & $\checkmark$ & $\checkmark$ & $\checkmark$ & $\checkmark$ & $\checkmark$ & $\checkmark$ & $\checkmark$ & & & $\checkmark$ & $\checkmark$ & $\checkmark$ & $\checkmark$ & $\checkmark$ \\
\hline L5 & & $\checkmark$ & $\checkmark$ & $\checkmark$ & $\checkmark$ & $\checkmark$ & & $\checkmark$ & $\checkmark$ & $\checkmark$ & & $\checkmark$ & & & & & & $\checkmark$ & & & & & & & \\
\hline L6 & $\checkmark$ & $\checkmark$ & $\checkmark$ & $\checkmark$ & $\checkmark$ & $\checkmark$ & & & $\checkmark$ & $\checkmark$ & & & $\checkmark$ & $\checkmark$ & $\checkmark$ & $\checkmark$ & & $\checkmark$ & & & & $\checkmark$ & & $\checkmark$ & \\
\hline L7 & $\checkmark$ & $\checkmark$ & $\checkmark$ & $\checkmark$ & $\checkmark$ & $\checkmark$ & $\checkmark$ & $\checkmark$ & $\checkmark$ & $\checkmark$ & & $\checkmark$ & $\checkmark$ & $\checkmark$ & $\checkmark$ & $\checkmark$ & $\checkmark$ & $\checkmark$ & & & $\checkmark$ & $\checkmark$ & $\checkmark$ & $\checkmark$ & $\checkmark$ \\
\hline L8 & $\checkmark$ & $\checkmark$ & $\checkmark$ & $\checkmark$ & & $\checkmark$ & & & $\checkmark$ & $\checkmark$ & $\checkmark$ & & & $\checkmark$ & $\checkmark$ & $\checkmark$ & & $\checkmark$ & & & $\checkmark$ & $\checkmark$ & & $\checkmark$ & $\checkmark$ \\
\hline L9 & $\checkmark$ & $\checkmark$ & $\checkmark$ & & $\checkmark$ & $\checkmark$ & & & $\checkmark$ & $\checkmark$ & & $\checkmark$ & $\checkmark$ & $\checkmark$ & $\checkmark$ & $\checkmark$ & & $\checkmark$ & & & & $\checkmark$ & & $\checkmark$ & $\checkmark$ \\
\hline L10 & $\checkmark$ & $\checkmark$ & & $\checkmark$ & & $\checkmark$ & & & $\checkmark$ & $\checkmark$ & & & $\checkmark$ & $\checkmark$ & $\checkmark$ & $\checkmark$ & & $\checkmark$ & & & & $\checkmark$ & $\checkmark$ & & \\
\hline L11 & $\checkmark$ & $\checkmark$ & $\checkmark$ & $\checkmark$ & $\checkmark$ & $\checkmark$ & & & $\checkmark$ & $\checkmark$ & & $\checkmark$ & $\checkmark$ & $\checkmark$ & $\checkmark$ & $\checkmark$ & $\checkmark$ & $\checkmark$ & & & & $\checkmark$ & & $\checkmark$ & $\checkmark$ \\
\hline L12 & $\checkmark$ & $\checkmark$ & $\checkmark$ & & $\checkmark$ & $\checkmark$ & & & $\checkmark$ & $\checkmark$ & & $\checkmark$ & $\checkmark$ & $\checkmark$ & $\checkmark$ & $\checkmark$ & & $\checkmark$ & & $\checkmark$ & & $\checkmark$ & $\checkmark$ & $\checkmark$ & $\checkmark$ \\
\hline M1 & & $\checkmark$ & & & & $\checkmark$ & & & $\checkmark$ & $\checkmark$ & & & & & & & & & & & & & & & \\
\hline M2 & & $\checkmark$ & $\checkmark$ & & $\checkmark$ & $\checkmark$ & & & $\checkmark$ & $\checkmark$ & & $\checkmark$ & & & & $\checkmark$ & & & & & $\checkmark$ & & & & \\
\hline M3 & & & $\checkmark$ & & $\checkmark$ & $\checkmark$ & & & $\checkmark$ & $\checkmark$ & & $\checkmark$ & $\checkmark$ & $\checkmark$ & $\checkmark$ & $\checkmark$ & & $\checkmark$ & & & & $\checkmark$ & & $\checkmark$ & $\checkmark$ \\
\hline M4 & & $\checkmark$ & $\checkmark$ & $\checkmark$ & $\checkmark$ & $\checkmark$ & & & $\checkmark$ & $\checkmark$ & & $\checkmark$ & $\checkmark$ & & $\checkmark$ & $\checkmark$ & & $\checkmark$ & & & & & & & \\
\hline M5 & & $\checkmark$ & & & & $\checkmark$ & $\checkmark$ & & $\checkmark$ & $\checkmark$ & & $\checkmark$ & & & & & & & & & & & & & \\
\hline M6 & & $\checkmark$ & $\checkmark$ & $\checkmark$ & $\checkmark$ & $\checkmark$ & $\checkmark$ & $\checkmark$ & $\checkmark$ & $\checkmark$ & & $\checkmark$ & & & & & & $\checkmark$ & & & $\checkmark$ & & & & \\
\hline M7 & & & $\checkmark$ & $\checkmark$ & $\checkmark$ & $\checkmark$ & & & $\checkmark$ & $\checkmark$ & & $\checkmark$ & $\checkmark$ & & $\checkmark$ & $\checkmark$ & & $\checkmark$ & & & $\checkmark$ & $\checkmark$ & & & \\
\hline M8 & $\checkmark$ & $\checkmark$ & $\checkmark$ & $\checkmark$ & & $\checkmark$ & $\checkmark$ & & $\checkmark$ & $\checkmark$ & & $\checkmark$ & $\checkmark$ & $\checkmark$ & $\checkmark$ & $\checkmark$ & & $\checkmark$ & & & & $\checkmark$ & & $\checkmark$ & $\checkmark$ \\
\hline M9 & & $\checkmark$ & $\checkmark$ & $\checkmark$ & & $\checkmark$ & & & $\checkmark$ & $\checkmark$ & & & & & & & & & & & & & & & \\
\hline M10 & & $\checkmark$ & $\checkmark$ & $\checkmark$ & & $\checkmark$ & & & $\checkmark$ & $\checkmark$ & & $\checkmark$ & & & & & & & & & & & & & \\
\hline M11 & $\checkmark$ & $\checkmark$ & $\checkmark$ & $\checkmark$ & & $\checkmark$ & & & $\checkmark$ & $\checkmark$ & & $\checkmark$ & $\checkmark$ & $\checkmark$ & $\checkmark$ & $\checkmark$ & & $\checkmark$ & & & & $\checkmark$ & $\checkmark$ & $\checkmark$ & $\checkmark$ \\
\hline M12 & & & $\checkmark$ & $\checkmark$ & $\checkmark$ & $\checkmark$ & & & $\checkmark$ & $\checkmark$ & & & & & & $\checkmark$ & & $\checkmark$ & & & & & & & \\
\hline M13 & $\checkmark$ & $\checkmark$ & $\checkmark$ & & & $\checkmark$ & & & $\checkmark$ & $\checkmark$ & & & $\checkmark$ & $\checkmark$ & $\checkmark$ & $\checkmark$ & & $\checkmark$ & & & $\checkmark$ & $\checkmark$ & & $\checkmark$ & $\checkmark$ \\
\hline M14 & $\checkmark$ & $\checkmark$ & $\checkmark$ & $\checkmark$ & $\checkmark$ & $\checkmark$ & & & $\checkmark$ & $\checkmark$ & & $\checkmark$ & $\checkmark$ & $\checkmark$ & $\checkmark$ & $\checkmark$ & & $\checkmark$ & & & & $\checkmark$ & & $\checkmark$ & $\checkmark$ \\
\hline $\mathrm{S} 1$ & & & $\checkmark$ & $\checkmark$ & & $\checkmark$ & & & $\checkmark$ & $\checkmark$ & & $\checkmark$ & $\checkmark$ & & & $\checkmark$ & & $\checkmark$ & & & $\checkmark$ & & & & \\
\hline $\mathrm{S} 2$ & & & $\checkmark$ & & & $\checkmark$ & & & $\checkmark$ & $\checkmark$ & & $\checkmark$ & & & & & & & & & & $\checkmark$ & & & $\checkmark$ \\
\hline S3 & $\checkmark$ & $\checkmark$ & $\checkmark$ & $\checkmark$ & & $\checkmark$ & & & $\checkmark$ & $\checkmark$ & & $\checkmark$ & $\checkmark$ & $\checkmark$ & & & & $\checkmark$ & & & & $\checkmark$ & & & \\
\hline S4 & & $\checkmark$ & $\checkmark$ & & & $\checkmark$ & $\checkmark$ & & $\checkmark$ & $\checkmark$ & & $\checkmark$ & $\checkmark$ & & & & & $\checkmark$ & & & & & & & \\
\hline S5 & & $\checkmark$ & $\checkmark$ & $\checkmark$ & & $\checkmark$ & & & $\checkmark$ & $\checkmark$ & & $\checkmark$ & & & $\checkmark$ & $\checkmark$ & & & & & $\checkmark$ & & & $\checkmark$ & \\
\hline S6 & & $\checkmark$ & $\checkmark$ & & $\checkmark$ & $\checkmark$ & & $\checkmark$ & $\checkmark$ & $\checkmark$ & & $\checkmark$ & & & & $\checkmark$ & & & & & & & $\checkmark$ & & \\
\hline S7 & & $\checkmark$ & $\checkmark$ & $\checkmark$ & $\checkmark$ & $\checkmark$ & $\checkmark$ & $\checkmark$ & $\checkmark$ & $\checkmark$ & & $\checkmark$ & & & & $\checkmark$ & & $\checkmark$ & & & & & & & \\
\hline S8 & & $\checkmark$ & $\checkmark$ & & $\checkmark$ & $\checkmark$ & & & $\checkmark$ & $\checkmark$ & & $\checkmark$ & & & & & & $\checkmark$ & & & & & & & \\
\hline S9 & $\checkmark$ & $\checkmark$ & $\checkmark$ & & & $\checkmark$ & & & $\checkmark$ & $\checkmark$ & & $\checkmark$ & $\checkmark$ & $\checkmark$ & $\checkmark$ & $\checkmark$ & & $\checkmark$ & & & & $\checkmark$ & $\checkmark$ & $\checkmark$ & $\checkmark$ \\
\hline $\mathrm{S} 10$ & & $\checkmark$ & $\checkmark$ & $\checkmark$ & $\checkmark$ & $\checkmark$ & & & $\checkmark$ & $\checkmark$ & & $\checkmark$ & & & $\checkmark$ & & & $\checkmark$ & & & $\checkmark$ & & & & \\
\hline
\end{tabular}

Notes

* "L", "M", "S" denote large-sized HEIs, middle-sized HEIs, small-sized HEIs, respectively.

" $\checkmark$ " indicates implementation of sustainability-related issue

The last issues relate to $\mathrm{ER}$, in which SD-enhancing educational system (ER1) (39.29 points, $\pm 11.54 \mathrm{SD})$ was the major issue over other related issues $(\mathrm{P}<0.05)$. It refers to a concept of experiential and action-oriented approaches by encouraging students to jointly work on projects with external communities as well as organize an open platform to share their innovative projects enhancing sustainability to the public. This is supported by Migliorini and Lieblein [46], who demonstrated success in applying this concept, resulting in an improvement of the student's core competencies for 
sustainable agriculture education. Furthermore, Caniglia et al. [47] concluded that an action-oriented approach is a key success factor in cultivating sustainability knowledge for students due to the complexity of sustainability contexts requiring a variety of knowledge to be integrated for solutions.

Overall, our result showed different prioritized issues compared with other countries, for example, Canada [27] and Columbia [19]. This is due to the different context in terms of current problems, culture, and public influence.

\subsection{Sustainability-related implementation across HEIs}

The implementation in accordance with the developed issues in each dimension are summarized in Figure 2 and Table 2.

\subsubsection{Contribution of UI-GreenMetric to HEI's sustainability} activities

According to the reviewing process on the available reports of HEIs, there are percentages of issues that the selected HEIs revealed in their reports. The HEIs are separated into 2 groups, which are UI GreenMetrics participants (Group 1) and NonUI GreenMetrics participants (Group 2). The comparison results are shown in Figure 2.

Group 1 revealed the information of Organization management (AD1) and Vision and Strategy (AD2) more than Group 2 in the reports with $94.1 \%$, whereas Group 2 presented only $5.3 \%$. On the contrary, Integrity and Ethics (AD3) are slightly observed in Group 2 reports more than Group 1 reports (89.5\% and $88.2 \%$, respectively).

Both HEI groups revealed Economic Transparency (EC1) and Economic Performance and Distribution (EC2) with $100 \%$. Group 2 presented the activities that related with Indirect Economic Impacts (EC4) (84.2\%) more than Group 1 (64.7\%), demonstrating more implementation of activities supporting the communities to enhance safety, wellness, or economic growth of the population. According to Financial Mechanism Promoting SD Investment (EC3), Group 1 presented the information in their reports $(23.5 \%)$, whereas Group 2 had not reported any related activity. These results show that the positive impact of participating in a green university ranking distinctly influences the institutions to propose funding for sustainable implementation in the campus. Many HEIs have paid effort to achieve campus sustainability because of the lack of an appropriate funding mechanism to engage the staff and students [30, 48].

For the social criteria, all of the HEIs presented the activities that were implemented with communities to address their Public engagement and involvement (SC3). Group 1 revealed the implementation for supporting the well-being of staff and students in the campus $(70.6 \%)$, which showed their consideration about health, safety, and well-being. Furthermore, Group 1 considerably showed the portion of gender in the administrator position and supported the facilities in HEI (64.7\%). On the other hand, Group 2 disclosed administrative activities of the institutions to the public more than Group 1 (21.1\% and $17.6 \%$, respectively). Moreover, Group 2 also presented supplier's products and services, which related that ethics followed the national regulation in the reports more than Group 1, with $21.1 \%$ and $11.8 \%$, respectively. Nevertheless, we believe that all of the Thai HEIs followed the national regulation, but Group 2 was considered to fill in the information in their reports.

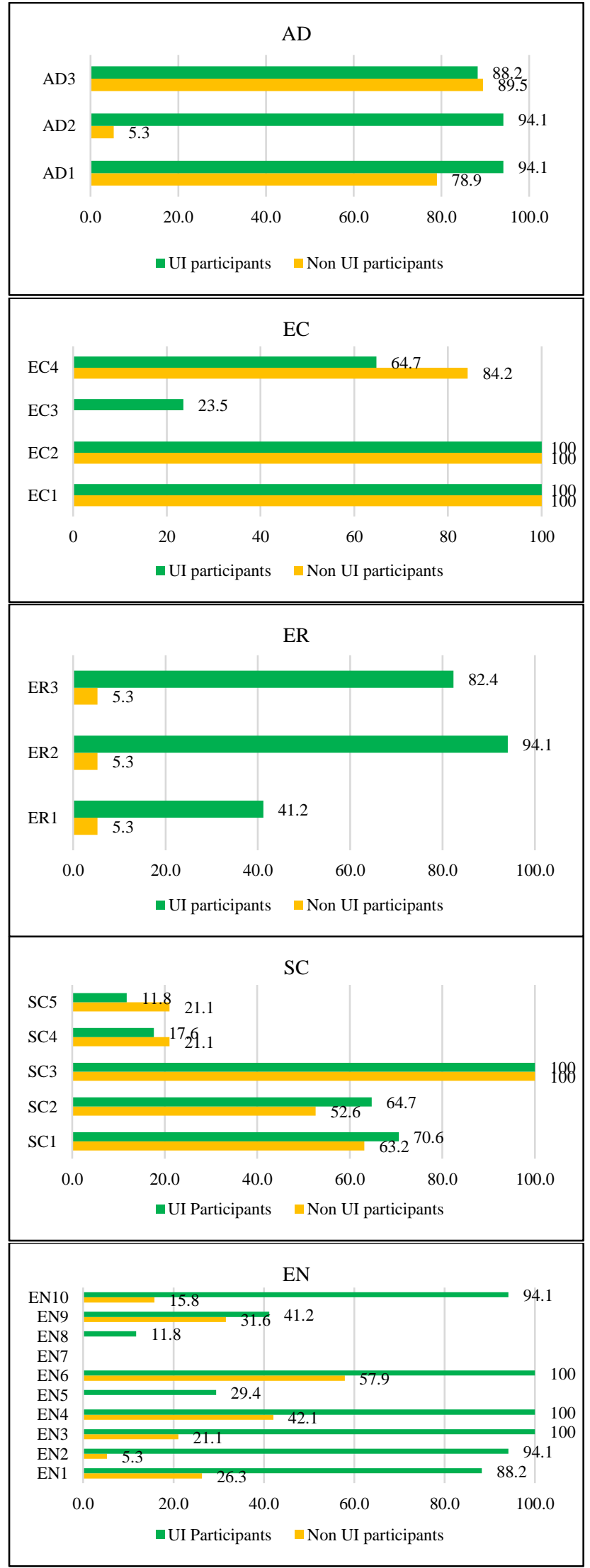

Figure 2. Percentage of implemented sustainable issues between UI GreenMetric participants and Non UI GreenMetric participant

Interestingly, the results distinctly show the large difference between Group 1 and Group 2 in Environmental criteria. Group 1 obviously addressed the environmental implementation of all issues more than Group 2, especially the 
issues that are covered in UI GreenMetric indicators, such as Transportation (EN3), Waste (EN4), and Energy conservation and efficiency (EN6) with 100\% followed by Climate change (EN2), Water (EN10), and Building \& construction (EN1) with $94.1 \%$ and $88.2 \%$. Surprisingly, there were no HEIs that revealed the Environmental compliance (EN7). The results demonstrate that green university rankings convince the institutions to consider and address environmental implementation in the reports because they specifically apply environmental indicators for the assessment [49]. This is consistent with the results by Atici et al. [31], who described that a green university ranking convinces the institutions to emphasize and develop policy approaching the environmentally-friendly campus.

As for education and research, it was distinctly shown that Group 1 considered to develop and adjust their education system to be more related to sustainability. They considered to fulfill the sustainable knowledge to their curriculums (94.1\%), support the educational system to embed the sustainable awareness to staff and students $(82.4 \%)$, and supported the researchers to discover new innovations related to sustainability in their research (41.2\%), whereas Group 2 had less educational system and research that support the sustainability $(5.3 \%)$. Therefore, it can be concluded that the sustainable education performance can be enhanced by a green university ranking because it encourages academics based on sustainability, which is the basic objective of a green ranking [50-53].

4.3.2 Comparison of statistical analysis in terms of size and UI-GreenMetric participation based on sustainability performance

Regarding correlation analysis between Administration (AD) issues and other issues, there were moderate to higher correlation in a pair of Organizational management (AD1) with Building and construction (EN1) $(r=0.69)$, Climate change (EN2) $(r=0.95)$, Transportation (EN3) $(r=0.69)$, Waste (EN4) $(r=0.51)$, Energy conservation and efficiency (EN6) $(r=0.51)$, Water (EN10) $(r=0.85)$, SD-integrated curriculum (ER2) $(r=0.78)$, and SD-related research (ER3) $(r$ $=0.69)$. However, there was no issue apparently correlating with Policy and strategy (AD2) and Integrity and ethics (AD3). This implies that AD1 strongly correlates with the implementation relating climate change and water, which requires a large amount of the financial budget.

In Figure 3, they clearly clustered into 2 groups, including a cluster representing a large-sized HEI mainly consisting of UI GreenMetric participants (10 out of 11) (Group 1) and another cluster representing small-to-medium HEIs or non-UI GreenMetric participants (Group 2). Group 1 was evaluated to obtain higher overall sustainability performance $(73.26$ points $\pm 13.81 \mathrm{SD}$ ) than the middle-sized HEIs (48.70 points \pm 17.43 SD) and small-sized HEIs (47.67 points \pm 12.78 SD). Since many large HEIs in Thailand are involved in UI GreenMetric, Group 1 indicated sustainability assessment tools as, in this case, it was UI GreenMetric that could significantly drive sustainability actions in $\mathrm{AD}, \mathrm{EN}$, and ER dimensions [22]. However, there was no enhancement in SC and EC dimensions. HEIs Group 2 could not demonstrate a clear sustainability implementation regardless of the dimensions, since UI GreenMetric indicators neglect issues of economic and social dimensions [24, 48, 49]. In addition, the results contradict our expectation regarding social issues. López-Pérez et al. [53] found that larger firms intensified the implementation of corporate social responsibility and linked with the business outcome of small-to-medium sized firms, as shown in our study.

It is noteworthy that the reviewed HEIs in this study were entirely governmental institutions. By this, implementation on economic dimension may be not prioritized. It is believed that sustainability is undoubtedly implemented in all HEI practice $[2,17,54]$, but they are compartmentalized [55]. This is especially the case for the Education/Research (ER) dimension, in which activities, curriculum, and research are often related to sustainability promotion. Hence, several issues implemented in HEIs may be neglected to be reported in public. All activities in HEIs should be systematized; thus, its outcome can be facilitated to address a linkage with sustainability.

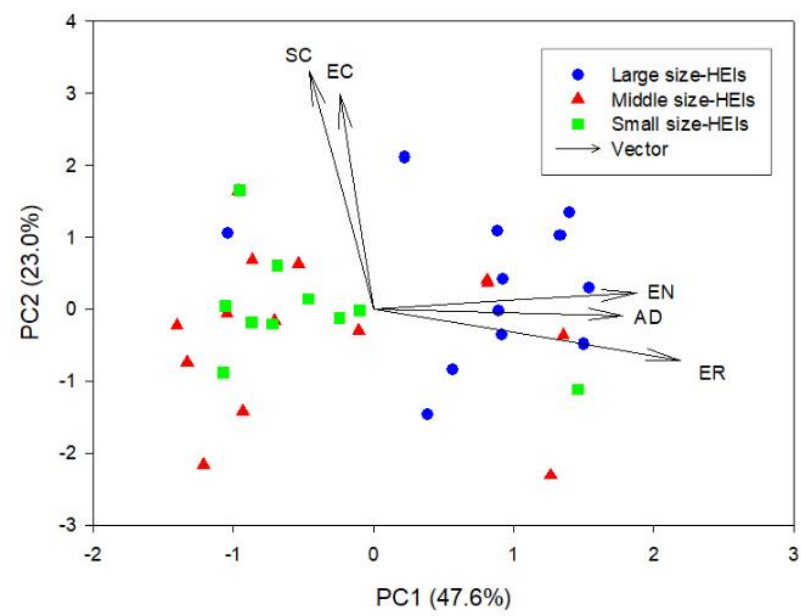

(a)

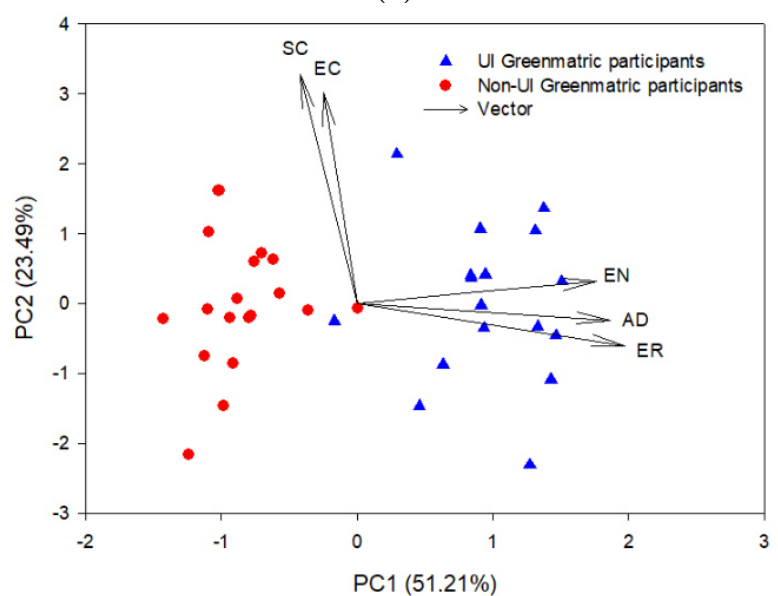

(b)

Figure 3. Results of principal analysis regarding relationships between dimension sustainability and overall sustainability performance scores across HEI categories (upper figure (a) indicates comparison by sizes, lower figure

(b) indicates comparison between UI GreenMetric participants and non-participants)

\section{CONCLUSION}

Our finding indicates policy and vision is critical as a first action for long-term sustainability achievement in HEIs. All sustainability issues covering administration, economic, social, environment, and education/research dimensions should be mutually integrated and simultaneously implemented. In practice, a new Thai HEI inexperienced in sustainability 
implementation may primarily consider emphasizing policy and vision, safety and well-being, waste, and SD-enhancing educational system, as they are fundamental issues according to this study's findings. Policy and vision are an important initial step for the development of a sustainability direction and its consequent financial support. Safety and well-being are critically an interlinking issue with other issues in other dimensions, such as environmental regulation compliance, green purchasing, ecosystem, and SD-educational system. Waste is another critical issue due to fundamental environmental problems in HEIs. Lastly, SD-enhancing educational system enhances experimental and action-oriented approaches, which is regarded as a key success for cultivating sustainability knowledge for students.

In this study, we were unable to conclude the effect of size as most of the large-sized HEIs are UI GreenMetric participants. The effect of size, therefore, remained inconclusive. However, it can be informed that large-sized Thai HEIs strongly commit to be a 'green university'. In addition, participation in UI GreenMetric is concluded to have a positive contribution to Thai HEI sustainability, especially for administration, environment, and education/research dimensions in respect to its indicators. Further extension of the rankings to include economic and social dimensions is recommended.

A limitation in this study that should be considered in future studies is described as follows. Firstly, the questionnaire respondents were mostly executive levels; therefore, the Administration dimension may be biased and relatively more weighted. Participation of academic and supporting staff as well as community leaders could provide interesting results. Secondly, future studies may try to include private HEIs in the analysis. Lastly, investigation of other sustainability assessment tools, such as THE Impact University Ranking, may provide more comprehensive results since the ranking includes all United Nations' Sustainable Development Goals (SDGs), which cover all sustainability dimensions. Nevertheless, the THE Impact Ranking has only been implemented in the past 2 years, so its contribution may be still unclear at this time.

\section{ACKNOWLEDGEMENT}

This work is financially supported by Thailand Science Research and Innovation and National Research Council of Thailand, under Grant no. RDG 6230022. The authors would like to express sincere gratitude to the Sustainable University Network of Thailand (SUN) for the participation and support.

\section{REFERENCES}

[1] Brundtland, G.H. (1985). World Commission on environment and development. Journal Environment Policy Law, 14(1): 26-30. https://doi.org/10.1016/S0378-777X(85)80040-8

[2] Cortese, A.D. (2003). The critical role of higher education in creating a sustainable future. Journal of Planning for Higher Education, 31(3): 15-22.

[3] Lukman, R., Glavic, P. (2007). What are the key elements of a sustainability university? Journal of Technology Environmental Policy, 9: 103-114 https://doi.org/10.1007/s10098-006-0070-7
[4] Saadatian, O., Haw, L.C., Mat, S., Sopian, K., Dalman, M., Salleh, E. (2011). Sustainable development in malaysia planning and initiatives. Recent Researches in Chemistry, Biology, Environment and Culture, 138-143.

[5] Amaral, L.P., Martins, N., Gouveia, J.B. (2013). Quest for a sustainable university: A review. Journal of Sustainability in Higher Education, 16(2): 156-172. https://doi/10.1108/IJSHE-02-2013-0017

[6] Alshuwaikhat, H.M., Abubakar, I. (2008). An integrated approach to achieving campus sustainability: Assessment of the current campus environmental management practices. Journal of Cleaner Production, 16(16): $1777-1785$. https://doi.org/10.1016/j.jclepro.2007.12.002

[7] Tangwanichagapong, S., Nitivattananon, V., Brahmanand, M., Visvanathan, C. (2017). Greening of a campus through waste management initiatives: Experience from a higher education institution in Thailand. International Journal of Sustainability in Higher Education, 18(2): 203-217. https://doi.org/10.1108/IJSHE-10-2015-0175

[8] Aleixo, A.M., Azeiteiro, U., Leal, S. (2017). The implementation of sustainability practices in Portuguese higher education institutions. Journal of Sustainability in Higher Education, 19(1): 146-178. http://dx.doi.org/10.1108/IJSHE-02-2017-0016

[9] ACUPCC. (2012) American College \& University Presidents' Climate Commitment IMPLEMENTATION GUIDE Version 2.1-2012. https://secondnature.org/wpcontent/uploads/ACUPCCImplementationGuide_V2.1_. pdf.

[10] Global Reporting Initiative. (2015). The GRI Standards. https://www.globalreporting.org/about-gri/.

[11] AASHE. (2017). Technical Manual STARS. Retrieved from. https://stars.aashe.org/. AASHE (The Association for the Advancement of Sustainability in Higher Education). Stars Technical Manual. Version 2.1. Available online: https://stars.aashe.org/pages/about/technicalmanual.html, accessed on Oct. 18, 2020.

[12] Universitas Indonesia. (2020). UI GreenMetric World University Ranking. http://greenmetric.ui.ac.id/, accessed on Oct. 18, 2020.

[13] Times, The World University Ranking. The University Impact Ranking. https://www.Timeshig hereducation.com/how-participate-times-highereducation-rankings, accessed on Oct. 18, 2020.

[14] Berzosa, A., Bernaldo, M.O., Fernández-Sanchez, G. (2017). Sustainability assessment tools for higher education: An empirical comparative analysis. Journal of Cleaner Production, 161: 812-820. https://doi.org/10.1016/j.jclepro.2017.05.194

[15] Hussey, D.M., Kirsop, P.L., Meissen, R.E. (2001). Global reporting initiative guidelines: an evaluation of sustainable development metrics for industry. Journal of Environmental Quality Management, 11(1): 1-20. https://doi.org/10.1002/tqem.1200

[16] Morhardt, J.E., Baird, S., Freeman, K. (2002). Scoring corporate environmental and sustainability reports using GRI 2000, ISO 14031 and other criteria. Journal of Corporate Social Responsibility Environmental Management, 9(4): 215-233. https://doi.org/10.1002/csr.26

[17] Lozano, R. (2006). Incorporation and institutionalization 
of SD into universities: Breaking through barriers to change. Journal of Cleaner Production, 14(9-11): 787796. https://doi.org/10.1016/j.jclepro.2005.12.010

[18] Lozano, R., Huisingh, D. (2011). Inter - linking issues and dimensions in sustainability reporting. Journal of Cleaner Production, 19(2-3): 99-107. https://doi.org/10.1016/j.jclepro.2010.01.004

[19] Gómezgutiérrez, D., Sepúlveda, J.A.M. (2018). Sustainability indicators for universities: revision for a Colombian case. Global Journal of Research in Engineering, 17(5): 1-10.

[20] Fombrun, C. (1996). Reputation: Realising Value from the Corporate Image. Harvard Business School Press, Boston.

[21] Suchman, M.C. (1995). Managing legitimacy: Strategic and institutional approaches. Academy of Management Review. Journal of Academy of Management Review, 20(3): 571-610. https://doi.org/10.2307/258788

[22] Bansal, P. (2005). Evolving sustainably: A longitudinal study of corporate sustainable development. Journal of Strategy Management, 26: 197-218. https://doi.org/10.1002/smj.441

[23] Gallo, P.J., Christensen, L.J. (2011). Firm size matters: An empirical investigation of organizational size and ownership on sustainability - related behaviors. Journal of Business Society, 50(3): 315-349. https://doi.org/10.1177/0007650311398784

[24] Alghamdi, N., Heijer, A., Jonge, H. (2016). Assessment tools' indicators for sustainability in universities: an analytical overview. Journal of Sustainability in Higher Education $18(1)$ :

84-115. https://doi.org/10.1108/IJSHE-04-2015-0071

[25] Gómez, F.U., Sáez-Navarrete, C., Lioi, S.R., Marzuca, V.I. (2015). Adaptable model for assessing sustainability in higher education. Journal of Cleaner Productin, 107: 475-485. https://doi.org/10.1016/j.jclepro.2014.07.047

[26] Ceulemans, K., Molderez, I., Liedekerke, L.V. (2015). Sustainability reporting in higher education: a comprehensive review of the recent literature and paths for further research. Journal of Cleaner Production, 106: 127-143. https://doi.org/10.1016/j.jclepro.2014.09.052

[27] Fonseca, A. (2011). The state of sustainability reporting at Canadian universities. International Journal of Sustainability in Higher Education, 12(1): 22-40. https://doi.org/10.1108/14676371111098285

[28] Filho, W.L., Wu, Y.C.J., Brandli, L.L., Avila, L.V., Azeiteiro, U.M., Caeiro, S., and Madruga, L.R.R.G. (2017). Identifying and overcoming obstacles to the implementation of sustainable development at universities. Journal of Integrative Environmental Sciences, $\quad$ 14(1): 93-108 https://doi.org/10.1080/1943815X.2017.1362007

[29] Whitehead, J. (2017). Prioritizing sustainability indicators: Using materiality analysis to guide sustainability assessment and strategy. Business Strategy and the Environment, 26: 399-412. https://doi.org/10.1002/bse.1928

[30] Filho, W.L., Will, M., Salvia, A.L., Adomßent, M., Grahl, A., Spira, F. (2019). The role of green and sustainability offices in fostering sustainability efforts at higher education institutions. Journal of Cleaner Production, 232: 1394-1401 https://doi.org/10.1016/j.jclepro.2019.05.273

[31] Atici, K.B., Yasayacak, G., Yildiz, Y., Ulucan, A. (2020).
Green university and academic performance: An empirical study on UI GreenMetric and world university rankings. Journal of Cleaner Production, 291: 125289. https://doi.org/10.1016/j.jclepro.2020.125289

[32] Caeiro, S., Sandoval Hamón, L.A., Martins, R., Bayas Aldaz, C.E. (2020). Sustainability assessment and benchmarking in higher education institutions - a critical $\begin{array}{lll}\text { reflection. } & \text { Sustainability, } & \text { 12(2): } 543 .\end{array}$ https://doi.org/10.3390/su12020543

[33] Shriberg, M. (2020). Institutional assessment tools for sustainability in higher education: Strengths, weakness, and inplications for practice and theory. Journal of Higher Education Policy, 15: 153-167. https://doi.org/10.1016/S0952-8733(02)00006-5

[34] Razak, D.A., Sanusi, Z.A., Jegatesen, G., KhelghatDoost, H. (2013). Alternative university appraisal (AUA) Reconstructing universities' ranking and rating toward a sustainable future. Sustainability Assessment Tools in Higher Education Institutions, 139-154. https://doi.org/10.1007/978-3-319-02375-5_8

[35] Roorda, N., Rammel, C., Waara, S., Fra Paleo, U. AISHE 2.0 Manual: Assessment Instrument for Sustainability in Higher

Education. http://www.eauc.org.uk/theplatform/aishe, accessed on Oct. 18, 2020.

[36] Sustainable Endowments Institute. The College Sustainability Report Card. http://www.greenreportcard.org/index.html, accessed on Oct. 18, 2020.

[37] Scialabba, N. (2014). SAFA Guidelines: Sustainability Assessment of Food and Agriculture Systems. Food and Agriculture Organization of the United Nations.

[38] Lardjane, S., Laveuve, F., Nuutinen, M. (2017). The need for fundamental change in education. Journal of Environmental Education, 12(2). https://doi.org/10.14712/18023061.552

[39] Velazquez, L., Munguia, N., Sanchez, M. (2005). Deterring sustainability in higher education institutions: An appraisal of the factors which influence sustainability in higher education institutions. Journal of Sustainability in Higher Education, 6(4): 383-391. http://dx.doi.org/10.1108/14676370510623865

[40] Sepasi, S., Rahdari, A., Rexhepi, G. (2018). Developing a sustainability reporting assessment tool for higher education institutions: The university of California. Journal of Sustainable Development, 26(6): 672-682. https://doi.org/10.1002/sd.1736

[41] Lukman, R., Krajnc, D., Glavic, P. (2010). University ranking using research, educational and environmental indicators. Journal of Cleaner Production, 18: 619-628. https://doi.org/10.1016/j.jclepro.2009.09.015

[42] Dooris, M., Doherty, S. (2010). Healthy universities time for action: a qualitative research study exploring the potential for a national program. Journal of Health Promotion International, 25(1): 94-106. https://doi.org/10.1093/heapro/daq015

[43] Dooris, M., Cawood, J., Doherty, S., Powell, S. (2010). Healthy universities: Concept, model and framework for applying the healthy settings approach within higher education in England. Final Project Report. http://www.healthyuniversities.ac.uk/uploads/fck/HUFinal_ReportFINAL_v2(1).pdf, accessed on Mar. 23, 2016.

[44] Freidenfelds, D., Kalnins, S.N., Gusca, J. (2018). What 
does environmentally sustainable higher education institution mean? Journal of Energy Procedia, 147: 4247. https://doi.org/10.1016/j.egypro.2018.07.031

[45] Knuth, S., Nagle, B., Steuer, C., Yarnal, B. (2007). Universities and climate change mitigation: Advancing grassroots climate policy in the US. Journal of Local Environment, 12(5): 485-504. https://doi.org/10.1080/13549830701657059

[46] Migliorini, P., Lieblein, G. (2016). Facilitating transformation and competence development in sustainable agriculture university education: An experiential and action oriented approach. Journal of Sustainability, 8 :

1243. https://doi.org/10.3390/su8121243

[47] Caniglia, G., Luederitz, C., Wirth, T., Fazey, I., MartínLópez, B., Hondrila, K., König, A., Wehrden, H., Schäpke, N.A., Laubichler, M.D., Lang, D.J. (2020). A pluralistic and integrated approach to action-oriented knowledge for sustainability. Journal of Nature Sustainability, 4: 93-100. https://doi.org/10.1038/s41893020-00616-z

[48] Bullock, G., Wilder, N. (2016). The comprehensiveness of competing higher education sustainability assessment. Journal Sustainability Higher Education, 17(3): 282-304. http://dx.doi.org/10.1108/IJSHE-05-2014-0078

[49] Ragazzi, M., Ghidini, F. (2017) Environmental sustainability of universities: critical analysis of a green ranking. Journal of Energy Procedia, 119: 111-120. https://doi.org/10.1016/j.egypro.2017.07.054

[50] Martins, A.A., Mata, T.M., Costa, C.A.V. (2006).
Education for sustainability: Challenges and trends. Journal of Clean Technologies and Environmental Policy, 8: 31-37. https://doi.org/10.1007/s10098-005-0026-3

[51] Puertas, R., Marti, L. (2019). Sustainability in universities: DEA - GreenMetric. Journal of Sustainability 11: 3766. https://doi.org/10.3390/su11143766

[52] Muñoz-Suárez, M., Guadalajara, N., Osca, J.M. (2020). A comparative analysis between global university ranking and environmental sustainability. Journal of Sustainability, 12 : https://doi.org/10.3390/su12145759

[53] López-Pérez, M.E., Melero-Polo, I., Vázquez-Carrasco, R., Cambra-Fierro, J. (2018). Sustainability and business outcomes in the context of SMEs: Comparing family firms vs. non-family firms. Journal of Sustainability, 10: 4080. https://doi.org/10.3390/su10114080

[54] Lozano, R., Lukman, R., Lozano, F.J., Huisingh, D., Lambrechts, W. (2013). Declarations for sustainability in higher education: Becoming better leaders, through addressing the university system. Journal of Cleaner Production, 4 : 10-19. https://doi.org/10.1016/j.jclepro.2011.10.006

[55] Lozano, R., Ceulemans, K., Alonso-Almeida, M., Huisingh, D., Lozano, F., Wass, T., Lambrechts, W., Lukman, R., Hugé, J. (2015). A review of commitment and implementation of sustainable development in higher education: results from a worldwide survey. Journal of Cleaner Production, 108: 1-18. https://doi.org/10.1016/j.jclepro.2014.09.048 